\title{
Specifying production times in the ACT-R cognitive modeling system using evoked response potential latency
}

Daniel N Cassenti', Anthony J Ries

From Twenty First Annual Computational Neuroscience Meeting: CNS*2012

Decatur, GA, USA. 21-26 July 2012

An Adaptive Control of Though Rational (ACT-R, [1]) model was built to simulate the results of an experiment that tested the relationship between brain dynamics measured with event-related potentials (ERPs) and cognitive processing associated with mathematical rule matching by having participants decide whether a presented number fit a predefined mathematical rule. Specifically, we used the latency of the N1 and P3 ERP components to assess differences in time to perceptual encoding [2] and context updating [3] respectively across three numerical rule matching conditions: Negative (press a button if the number is negative), Odd (press if the number is odd), and Complex (press if the number is negative and greater than -6 or greater than 5). First, it was hypothesized that participants would take an equal amount of time to perceptually encode a number regardless of rule difficulty and therefore N1 latency would be unchanged across levels of rule complexity. Second, it was hypothesized that P3 latency would be longer with more difficult rules since updating contextual memory cannot occur until the participant classified the stimulus as following or not following the rule. The results of the study supported

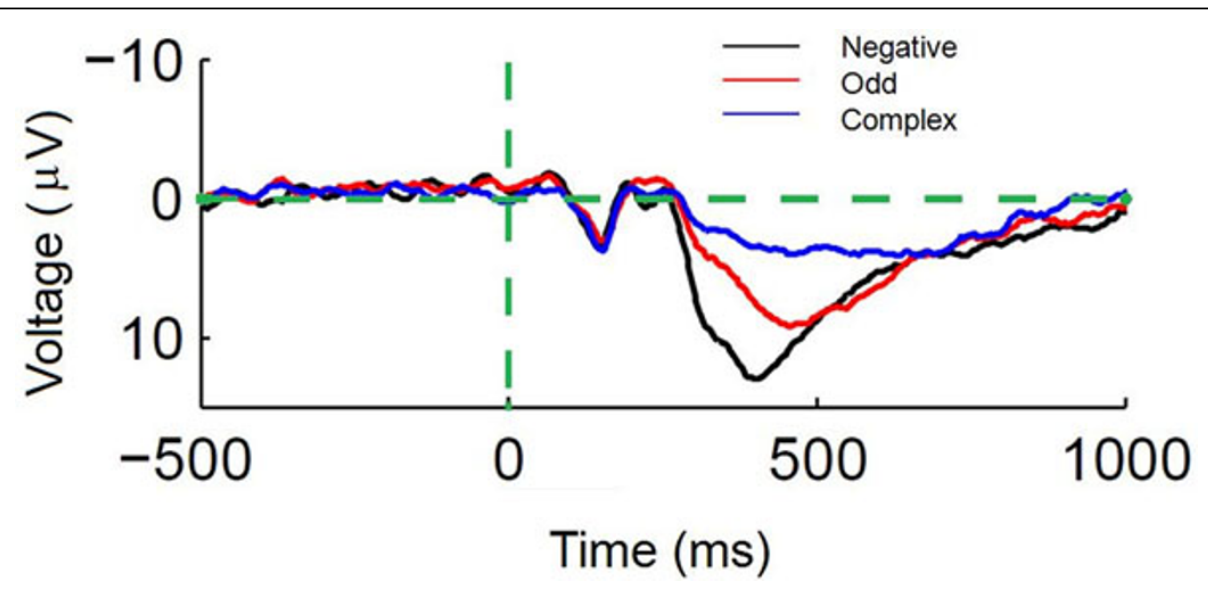

Figure 1 The ERP waveform at electrode site Pz, where P3 was evaluated as the latency marking 50\% of the area under the P3 curve. Deciding whether a presented number was negative was least difficult and had the earliest P3 latency. Deciding whether the number was odd had middling difficulty and P3 latency. Deciding if the number was in one of two divergent parts of the number line (i.e., Complex) was most difficult and had the longest P3.

\footnotetext{
* Correspondence: daniel.n.cassenti.civ@mail.mil

Human Research and Engineering Directorate, U.S. Army Research

Laboratory, APG, MD 21005, USA
}

\section{(Ciomed Central}

(c) 2012 Cassenti and Ries; licensee BioMed Central Ltd. This is an Open Access article distributed under the terms of the Creative Commons Attribution License (http://creativecommons.org/licenses/by/2.0), which permits unrestricted use, distribution, and reproduction in any medium, provided the original work is properly cited. 
these hypotheses showing that N1 latency did not change based on rule, whereas P3 latency increased with rule complexity (Figure 1).

Using the same method as had been previously established [3], model building consisted of determining the necessary productions (i.e., mental steps in ACT-R), arranging the productions, and assigning production times to simulate the timing of the cognitive correlates of the ERPs. This process specified production times in ACT-R that may be used in new models instead of relying on default and arbitrary assignment of production times.

Published: 16 July 2012

\section{References}

1. Anderson JR, Lebiere C: The Atomic Components of Thought. Mahwah, NJ: Erlbaum; 1998

2. Skrandies $W$, Rammsayer $T$ : The perception of temporal structure and auditory evoked brain activity. Bio Psych 1995, 40:267-280.

3. Donchin E, Coles MGH: Is the P300 component a manifestation of context updating? Beh Brain Sci 1988, 11:357-374.

4. Cassenti DN, Kerick SE, McDowell K: Observing and modeling cognitive events through event related potentials and ACT-R. Cog Sys Res 2011, 12:56-65.

doi:10.1186/1471-2202-13-S1-P62

Cite this article as: Cassenti and Ries: Specifying production times in the ACT-R cognitive modeling system using evoked response potential latency. BMC Neuroscience 2012 13(Suppl 1):P62.

\section{Submit your next manuscript to BioMed Central} and take full advantage of:

- Convenient online submission

- Thorough peer review

- No space constraints or color figure charges

- Immediate publication on acceptance

- Inclusion in PubMed, CAS, Scopus and Google Scholar

- Research which is freely available for redistribution

Submit your manuscript at www.biomedcentral.com/submit
C Biomed Central 